6.4B THE MOBILE SOUSY-DOPPLER RADAR - TECHNICAL DESIGN AND FIRST RESULTS

P. Czechowsky, G. Schmidt and R. Ruster

Max-Planck-Institut fur Aeronomie

D-3411 Kat lenburg-Lindau

Federal Republic of Germany

\begin{abstract}
Based on the experience obtained with the stationary sousy radar in the Harz mountains, a mobile VHF Doppler system was developed during the last two years. The electronic part is installed in a $20-\mathrm{ft}$ container and was tested for the first time during a joint experiment at the Arecibo Observatory (Puerto Rico) using a special log-periodic aerial to illuminate the $300-\mathrm{m}$ dish. In 1982 this system was extended by designing a mobile phased antenna array with finally 576 Yagi elements. The grouping of the single Yagis, the system of transmission lines, the phase shifters, the power splitters and the T/R-switch are described. A summaxy of results obtained during the first two campaigns is presented as well as a survey of future programs demonstrating the flexibility of this mobile system.
\end{abstract}

\title{
INTRODUCTION
}

During the 1ast decade the development of the upcoming VHF-Doppler radars designed to study the structure and dynamics of the middle and lower atmosphere was mainly influenced by the demand to improve the efficiency of these systems. The power-aperture-product, therefore, was increased using larger antennas and transmitters and different pulse coding techniques (e.g., BALSLEY et al., 1979; CZECHOWSKY et a1., 1979). The height and time resolution as well as the steerability of the phased antenna arrays were extended and other methods well known from ionospheric research, such as the spaced antenna drift technique. were applied to investigations of the middle atmosphere (ROTTGER and VINCENT. 1978).

At the same time the sousy radar facility was extended by a second system which is completely mobile, in order to increase the flexibility and to enable participation in other scientific programs studying geographical or orographical influences.

The purpose of this paper is to describe the technique and design of the sousY mobile radar in comparison to the stationary system. which has been in operation since 1977, and to discuss first results obtained during common experiments at the Arecibo Observatory and during the ALPEX campaign. Finally, a brief outline of future programs is presented.

\section{THE STATIONARY SYSTEM}

The sousy radar was designed in 1975 and completed after successful test measurements in summer 1977. This system is located in a valley in the Harz mountains (lat. $51^{\circ} 42^{\prime} \mathrm{N}$, long. $10^{\circ} 30^{\prime} \mathrm{E}$ ) $26 \mathrm{~km}$ east of Lindau, in order to minimize interference with TV systems operating at the same frequency and to reduce ground clutter from distances behind the surrounding mountains. Since the radar has already been described in detail by SCHMIDT et al. (1978), only a brief summary of the most important technical parameters are presented in the block diagram of Figure la.

The minimum usable pulse length is 1 us corresponding to a height resolution of $150 \mathrm{~m}$. During some scientific programs, however, a special sampling technique was applied to improve the resolution to about $20-30 \mathrm{~m}$ (ROTTGER and SCEMIDT, 1979). The tran'smitter peak power is $600 \mathrm{~kW}$ with a maximum duty cycle 


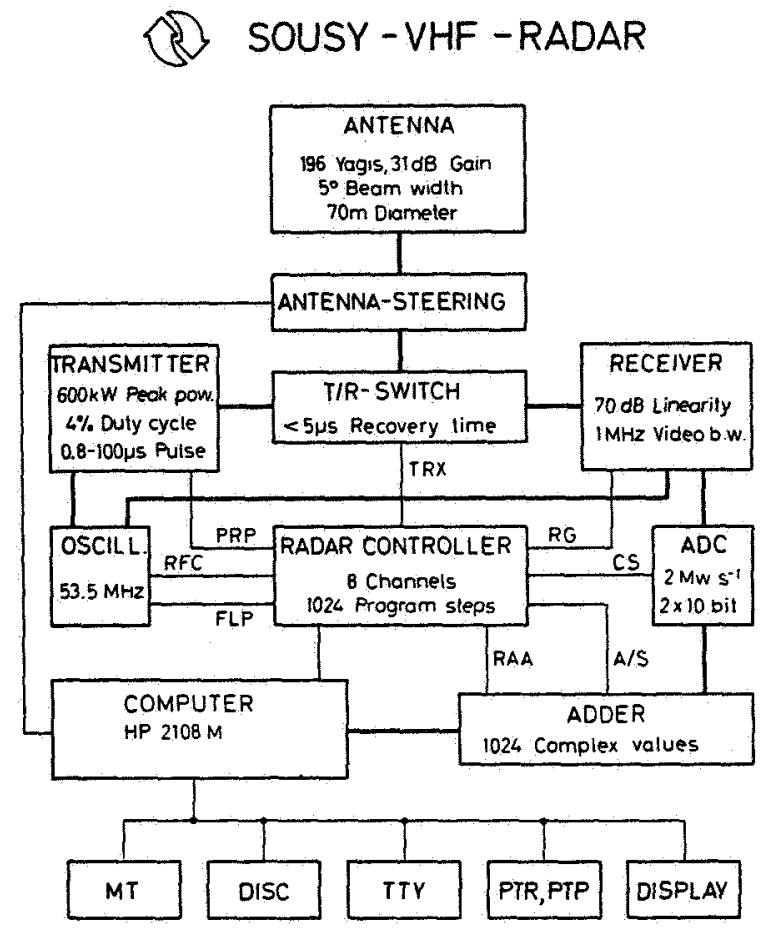

Figure 1a. Block diagram of the SOUSY stationary radar in the Harz mountains/Germany.

of $4 \%$. The power supply is capable of handling a maximum length of $100 \mu \mathrm{s}$. The final amplifier - a modified Philips TV transmitter -- operates in a pushpull mode using two water-cooled tetrodes. Phase coding was introduced to improve the signa1-to-noise ratio especially for mesospheric observations. The radar transmitter and receiver is tunable in the frequency range from 48 to 67 $\mathrm{MHz}$ (Table 1). The receiver has a video bandwidth of $1 \mathrm{MHz}$ and a linear amplification within a dynamic range of $70 \mathrm{~dB}$ to enable hardware coherent integration. The complex signals at the receiver quadrature output are digitized using a 10-bit $A D C$ and coherently added by a hardware adder with a maximum

Table 1.

\begin{tabular}{llc}
\hline & STATIONARY SYSTEM & MOBILE SYSTEM \\
\cline { 2 - 3 } Pulse peak power & $600 \mathrm{~kW}$ & $200 \mathrm{~kW}$ \\
Duty cycle & $4 \%$ & $4 \%$ \\
Number of elements & 196 & 576 \\
Single element & $4-e l e m e n t$ Yagi & $4-e l$ ement Yagi \\
Polarization & 1 inear & linear \\
Effective area & $3150 \mathrm{~m}^{2}$ & $8880 \mathrm{~m}^{2}$ \\
Gain & $31 \mathrm{~dB}$ & $35.5 \mathrm{~dB}$ \\
Steerability & continuously & 3 independent \\
& & directions \\
Frequency & $53.5 \mathrm{MHz}$ & $53.5 \mathrm{MHz}$ \\
Tuning & $47-64 \mathrm{MHz}$ & $45-58 \mathrm{MHz}$ \\
Beam width & $5^{\circ}$ & $3^{\circ}$ \\
Pulse length & $1-100 \mu \mathrm{Ms}$ & $1-100 \mu \mathrm{s}$ \\
\hline
\end{tabular}


storage for 1024 complex height values. The central unit is a radar controller which is programmed by a computer.

Pulse length, repetition frequency and coding are adjustable by software instructions based on the requirements of the scientific programs. Transmitter, receiver and antenna are connected to a high-speed transmit-receive-switch (TRswitch) with a recovery time of less than $8 \mu \mathrm{s}$. This corresponds to the nearfar-field range $R$ of the antenna which is about $1700 \mathrm{~m}\left(R=2 \mathrm{~d}^{2} / \lambda, d=\right.$ diameter of the antenna and $\lambda$ = wavelength). This antenna is an extension of a first version of 76 Yagis which was in operation from April 1977 to June 1978. A detailed description of this phased array is given below in the following section, since both antennas are based on the same concept.

\section{THE MOBILE SYSTEM}

The mobile SOUSY radar (Figure 1b) was developed to increase the flexibility and to enable participation in other scientific programs studying geographical or orographical influences. This system will be completed in summer 1983 and can be operated using different final amplifiers resulting in different average power-aperture-products from $1.4 \times 10^{6}$ to $7.1 \times 10^{7} \mathrm{Wm}^{2}$, the maximum of which is equal to the value of the stationary radar. The computer, the radar controller, the hardware adder and the $A D$ converter are exchangable between both systems whereas the transmitter and the receiver are constructed in a compact version to be completely installed in a single 20-ft container.

The final power amplifier -- a modified Philips TV module - is aircooled and operates in a class-C push-pul1 mode with a peak pulse power exceeding

\section{SOUSY MOBILE RADAR}

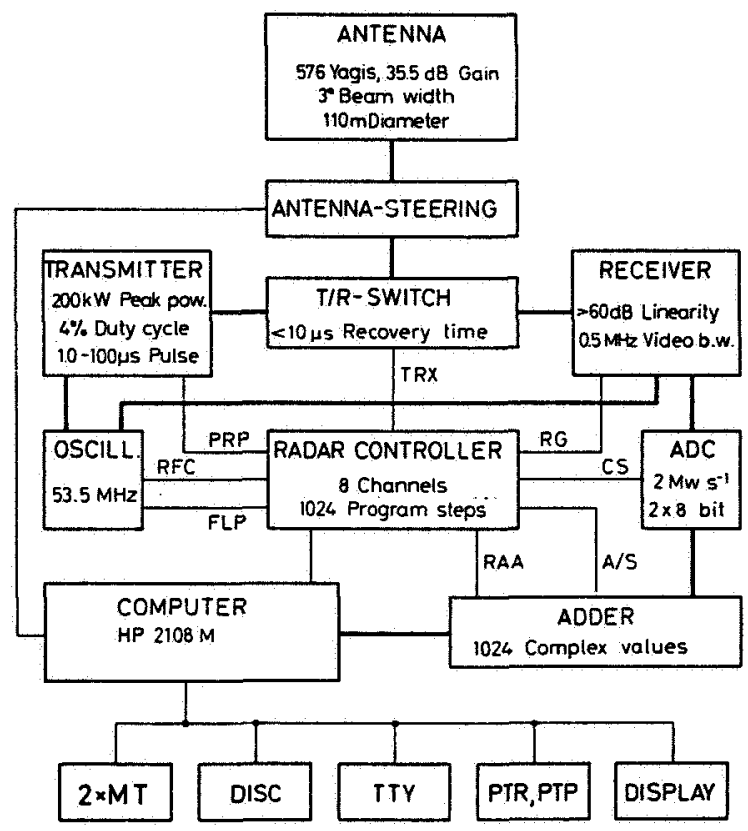

Figure 1b. Block diagram of the SOUSY mobile radar. 
$200 \mathrm{~kW}$. Different drivers can be used separately with 4, 10 and $35 \mathrm{~kW}$ for low power operation. This system is continuously tunable from 45 to $56 \mathrm{MHz}$.

Between tranomitter and antenna a bandpass filter with a bandwidth of 2 MHz and a low pass filter with a cut-off frequency at about $65 \mathrm{MHz}$ is inserted to prevent harmonic signals and TV interference. Since the mobile system is to be used at different geographical locations with different orographic shielding, special efforts were necessary to develop an antenna array that satisfies the requirements of maximum sidelobe suppression especially at low elevation angles. Therefore the construction of the antenna, the calculation of the radiation pattern as well as the description of TR switch and phase shifters are main subjects of this paper. Results and experiences obtained with the stationary array are also discussed in some detail.

\section{(a) Antenna Array}

The design criteria of the mobile system are mainly derived from the concept of the existing stationary phased array antenna which is now in operation in its final version since 1978 (CZECHOWSKY and MEYER, 1980). This first completely steerable antenna was developed to increase the efficiency of the whole radar system by preventing clutter and interference with other users since the operation frequency band of $f=53.5 \pm 1 \mathrm{MHz}$ fills the gap between colour and sound carrier of channel 2 of the German TV system. The frequency allocation therefore was coupled with the obligation to minimize the horizontally directed radiation. Consequently, the radar was located in a valley in the Harz mountains about $26-\mathrm{km}$ east of the institute at Lindau. These mountains provide a considerable shielding up to elevation angles of $5^{\circ}$ to $25^{\circ}$ at different azimuths within a $2-\mathrm{km}$ range. Since this distance is equal to that resulting from the near-far-field condition of the radiation pattern of the antenna the altitude of $2 \mathrm{~km}$ defines the lower limit of the sOUSY radar. Ground clutter from targets behind the shielding mountains was only detected during atmospheric conditions with strong ducting.

The second aspect to reduce interference can be achieved by the suppression of sidelobes which in turn requires an optimizing technique for calculating the antenna diagram. Operation in a TV channel has, of course, the advantage that several modules such as transmitter modules, the Yagi antennas, and power splitters could be bought from stock and were immediately ready for operation with slight modifications only. This advantage influenced the decision to use 4-element Yagis as single radiators instead of coaxial collinear dipoles of other systems.

The two phased arrays which are now in operation consist mainly of the same modules as e.g., 4-element Yagis, 3-dB power splitters, coaxial relays combined to phase shifters and different types of cables and connectors. The differences between the two systems lie in the size, the weighting of the Yagis, and the construction of the aerial masts. The technical parameters are summarized in Table 1.

The aperture of the first antenna array - the stationary one - is mechanically and electrically weighted in order to suppress the sidelobes by 25 $\mathrm{dB}$ at angles close to the zenith and by $40 \mathrm{~dB}$ at low elevation angles. This weighting is achieved by increasing the element spacing from $0.77 \lambda$ to $1.17 \lambda$ at the outermost positions and by feeding the antennas with different power, respectively.

The radiation pattern of $n$ Yagis each fed with a current amplitude $J_{v}$ can be expressed by (HEILMANN, 1970): 


$$
\left.E \approx F(\phi, \theta) \sum_{\nu=0}^{n-1}\left|J_{\nu}\right| e^{j\left(\frac{2 \pi d}{\lambda}\right.} \sin \theta \cos \left(\phi-\phi_{\nu}\right)-\delta_{\nu}\right),
$$

where $d_{v}$ and $\phi_{v}$ are the polar coordinates of an individual Yagi. For a given direction $\phi_{\mathrm{m}}$ and $\theta_{\mathrm{m}}$ the field strength $\mathrm{E}$ has a maximum if $\delta_{v}=2 \pi \mathrm{d}_{v} \cdot \sin \theta_{\mathrm{m}}$ $\cos \left(\phi_{\mathrm{m}}-\phi_{\nu}\right) / \lambda$. The variables used for the optimization of the antenna pattern are: (1) the diagram $F(\phi, \theta)$ of the single element; (2) the number $n$ of elements; (3) the polar coordinates $d_{v}$ and $\phi_{\nu}$; and (4) the current distribution $\mathrm{J}_{\mathrm{v}}=\left|\mathbf{j}_{\nu}\right| \cdot \mathrm{e}^{-j \delta_{\nu}}$

The method which was applied for calculating the configuration of an array with an optimum radiation pattern is called "evolution strategy" and is based on the principle of "mutation" and "selection". As an initial condition a realistic configuration of the $n$ elements is chosen to calculate a first diagram. Adding random variations to the original parameters a second diagram is computed and compared with the first one. If the second solution appears to be an improvement the new one is used as initial value for a further modification or "mutation". Otherwise the first "mutation" is cancelled and the original configuration is used for another "mutation". This latter procedure is called the "selection". Depending on the initial values up to twenty successive steps were necessary to find the optimum solution in calculating the radiation pattern of the first stationary antenna system. The coupling between the Yagi antennas as well as the reflection from the ground were neglected in the calculation since preliminary measurements have shown that the decoupling between the antennas -- independent of the polarization - is above $25 \mathrm{~dB}$ and that the front-to-back-ratio is about $15 \mathrm{~dB}$.

Because of the large number of elements in the mobile system, electrical weighting only was sufficient to assure a current distribution close to the Dolph-Chebychev distribution. The 576 Yagis of the mobile version, therefore, are located on straight lines with the same spacing.

For the mobile array Figure 2 shows the resulting current distribution (dots) in two planes at $\phi=0^{\circ}$ and $\phi=45^{\circ}$ to the dipole direction. The three solid lines represent the binominal (BI) and Dolph-Chebychev distributions with theoretical sidelobe suppression of $30 \mathrm{~dB}\left(\mathrm{DT}^{1}\right)$ and $60 \mathrm{~dB}\left(\mathrm{DT}^{2}\right)$.

\section{SOUSY MOBILE RADAR}

Amplitude Distribution

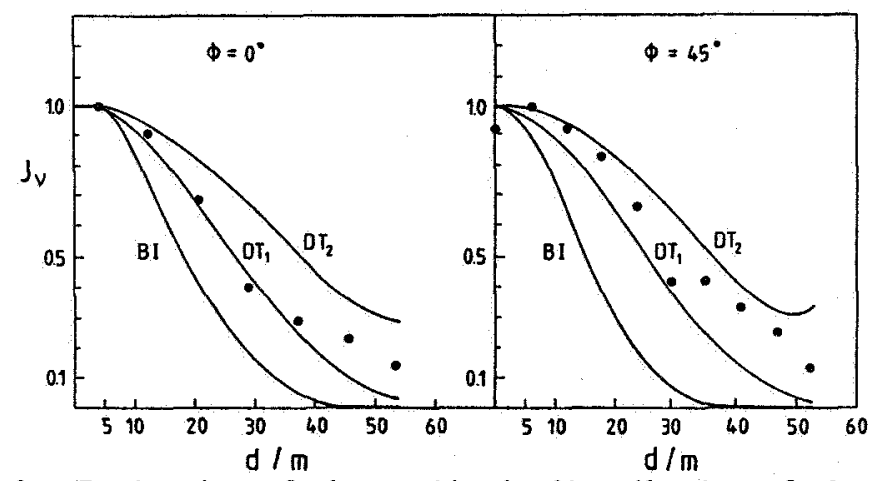

Figure 2. Projection of the amplitude distribution of the mobile SOUSY antenna compared with Dolph-Chebychev (DT1: $30 \mathrm{~dB}$ sidelobe suppression and $\mathrm{DT}_{2}: 60 \mathrm{~dB}$ sidelobe suppression) and a binominal (BI) distribution. 
Figure 3 presents the final diagram of the mobile antenna array for the plane $45^{\circ}$ to the dipole direction indicating a sidelobe reduction of at least 25 $\mathrm{dB}$ close to the main lobe and of $40 \mathrm{~dB}$ for low elevation angles. The half power beam width is $3^{\circ}$.

The above-mentioned method for obtaining an optimum radiation pattern as well as all assumptions made have been tested by comparing the theoretical and measured antenna diagram. For this purpose the stationary array located in the Harz mountains which is continuously steerable within a cone of $30^{\circ}$ vertex angle centered on the vertical has been used. This system was operated in the receiving mode only during the transit of Cassiopeia $A$, which is the most intense point source detectable for the SOUSY radar. The beam direction was tilted meridionally in steps of one degree from $12^{\circ}$ north to $8^{\circ}$ south within 1.5-min sweeps for a time interval of 3 hours on Oct. 25, 1981. Figure 4 presents in a three-dimensional plot the received noise power $P_{N}$ as a function of time and zenith distance. The power maximum was observed exactly at $7^{\circ}$ north which agrees with the position of Cassiopeia $A\left(\theta=58^{\circ} 35^{\prime} \mathrm{N}\right.$, SOUSY radar location $51^{\circ} 42^{\prime} N$ ), confirming the correct operation of the antenna steering. A detailed analysis (Figure 5) indicated that the measured half-power beam widths in the zonal and meridional planes for the tilted antenna deviate by $\pm 0.1^{\circ}$ from the theoretical value of $5.6^{\circ}$. Unfortunately it was not possible to measure the suppression of the sidelobes applying that method since the level of the background noise was only $10-15 \mathrm{~dB}$ below those of the point source.

The final configuration of the mobile array is shown in Figure 6 consisting of 144 squared subsystems with 4 Yagis each. The antenna aperture has approximately an octogonal shape and is electrically weighted, indicated by the different symbols. The black subsystems in the center are fed with a power level "1", the white ones with " 0.25 " and only a few ones (grey) are fed with " 0.5 " to smooth the current distribution. At present the steerability of this system is limited to three independent beam directions only.

\section{(b) Feeding Network}

The feeding network for both antenna arrays is based on the same concept and consists of a system of broadband 3-dB directional couplers and quadruple power splitters arranged in a nine-level cascade. A quarter of the scheme of

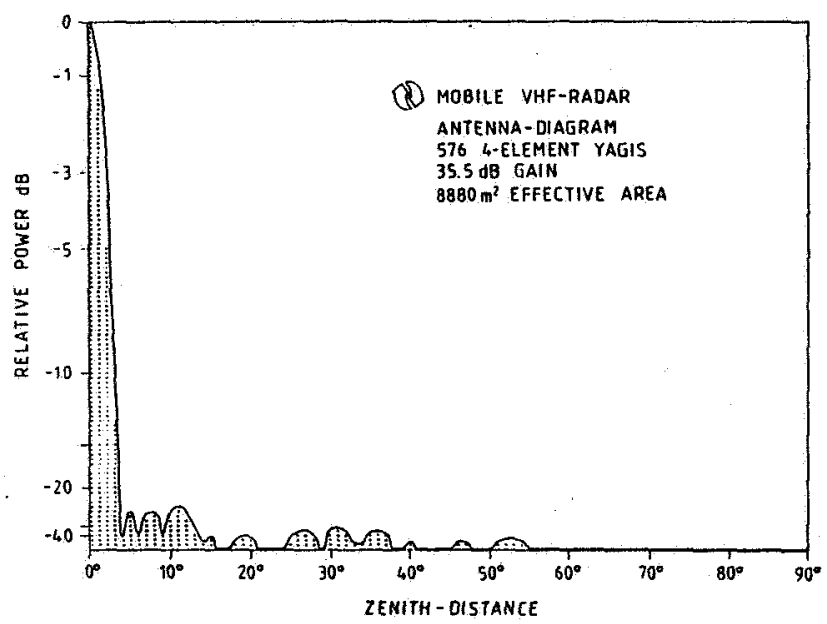

Figure 3. Diagram of the mobile SOUSY antenna, 


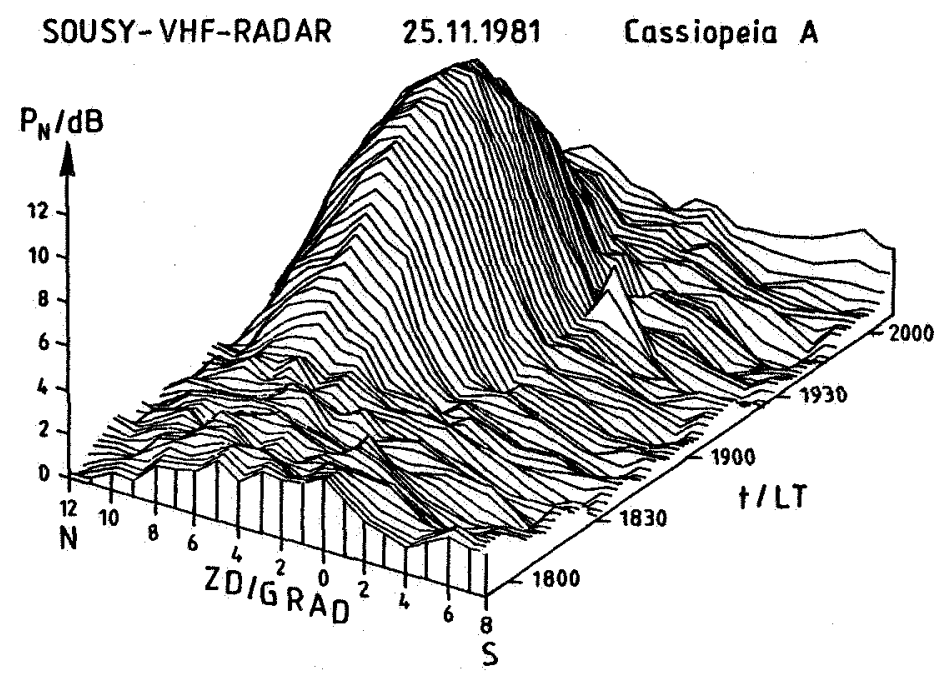

Figure 4. Received noise power $\mathrm{P}_{\mathrm{N}}$ of Cassiopeia A using the steerable stationary SOUSY antenna.

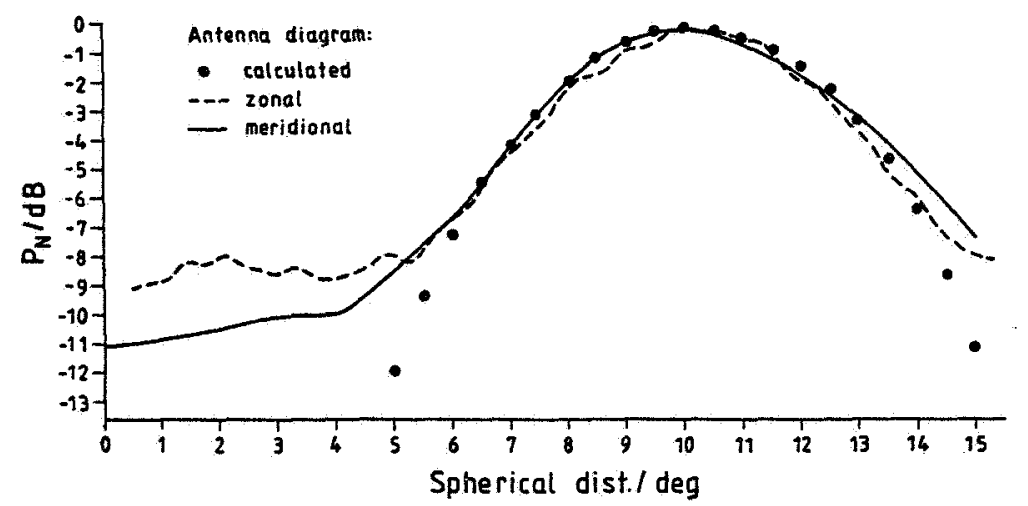

Figure 5. Calibration of the stationary SOUSY antenna with Cassiopeia A.

cables, power splitters, phase shifters and antennas is shown in Figure 7 starting at the third level of the cascade with an input power of $50 \mathrm{~kW}$.

The decoupling between the two output ports of each directional coupler of about $35 \mathrm{~dB}$ prevents a direct connection between the single antennas. Consequently the main part of the reflected power caused by the VSWR is fed back to the transmitter or is absorbed in the terminating resistors at each hybrid (VSWR $=1.15$ ) measured for the stationary antenna.

Due to the phase difference of $90^{\circ}$ between the two output ports of each hybrid, four phase values $\left(0^{\circ}, 90^{\circ}, 180^{\circ}, 270^{\circ}\right)$ occur at the last level of the cascade. To balance these differences, the phases of $90^{\circ}$ and $270^{\circ}$ are transformed to $180^{\circ}$ and $0^{\circ}$ by inserting additiona $190^{\circ}$ phase cables and the resulting displacement of $180^{\circ}$ is compensated by two different antenna types with a direct and crossed connection to the driven dipole, which is indicated in this figure by the open and solid arrows. 


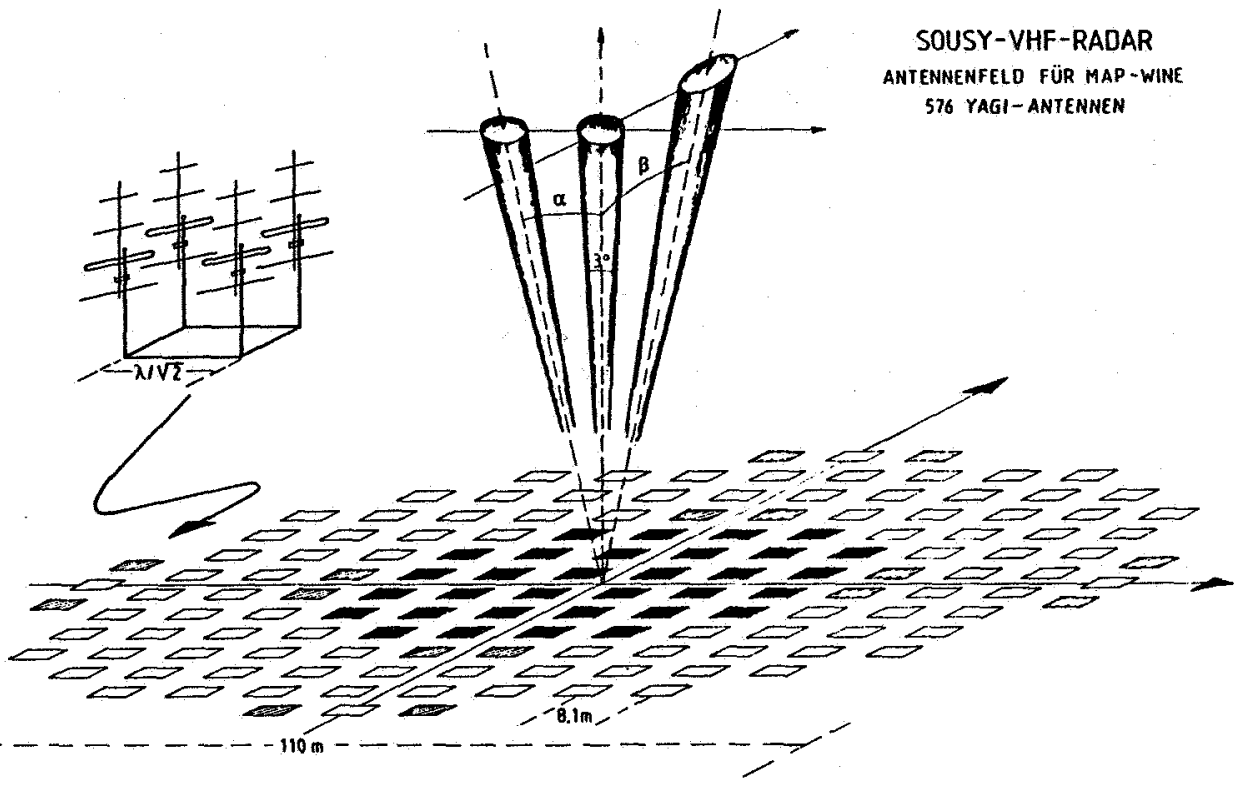

Figure 6. Configuration of the mobile soUSY antenna. (Weighted subsystems: black - power 1eve1 1; grey - power leve1 0.5, white - power leve1 0.25.)

Q Mobile VHF-Rodor

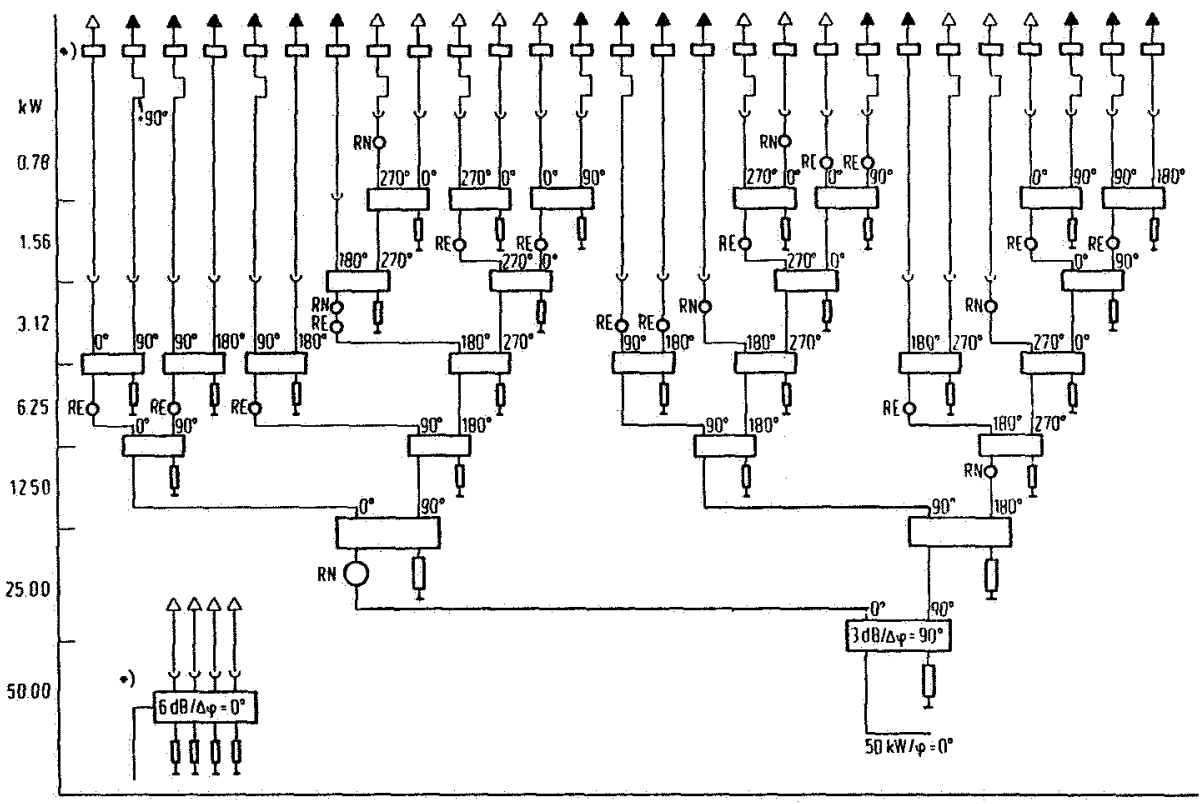

Figure 7. A quarter of the feeding system of the mobile antenna starting at the third level with $50 \mathrm{~kW}$. The circles represent the position of the phase shifters. 
The circles represent the position of the phase shifters which steer one or more subsystems each consisting of four antennas. This part of the antenna, the hybrids, and the phase shifters are the most expensive elements of the whole array.

\section{(c) 4-Bit Phase Shifter}

Figure 8 presents the principle of the 4-bit phase shifter, which is a combination of four 4-port coaxial switches. The phase can be changed in steps of $\lambda / 16$ equal to $22.5^{\circ}$ controlled by a computer program. In the "low" position all antennas are fed with equal phase and the beam is directed vertically. The switch-over-time of the relays is 1 es s than $50 \mathrm{~ms}$.

\section{(d) TR Switch}

The transmit-receive switch which connects the antenna with the transmitter and receiver is a combination of two $3-\mathrm{dB}$ directional couplers as shown in the Figure 9. This principle was first described by the Unitrode corporation (UNITRODE, 1968) in connection with the application of pin diodes in high-power duplexers.

The two hybrids are connected with a system of two cylindrical tubes where $2 \times 6$ high-power pin diodes are located on a circle between the inner and outer conductor. The switching pulse for the diodes is fed via a T-junction. The distance between the hybrid and the diodes is less than a quarter of a wavelength to reduce the high voltage of about $11 \mathrm{kV}$ (stationary system) at the connector.

In the transmit position the output power is split by the first hybrid, transferred to the pin diode switches, then reflected at these diodes and fed back to the decoupled port, which is connected with the antenna. During the receiving phase - with open diodes - the signal from the antenna is split in the first hybrid, passes the tubes, is combined in the second hybrid, and fed into the receiver. This system is capable of handling $600 \mathrm{~kW}$.

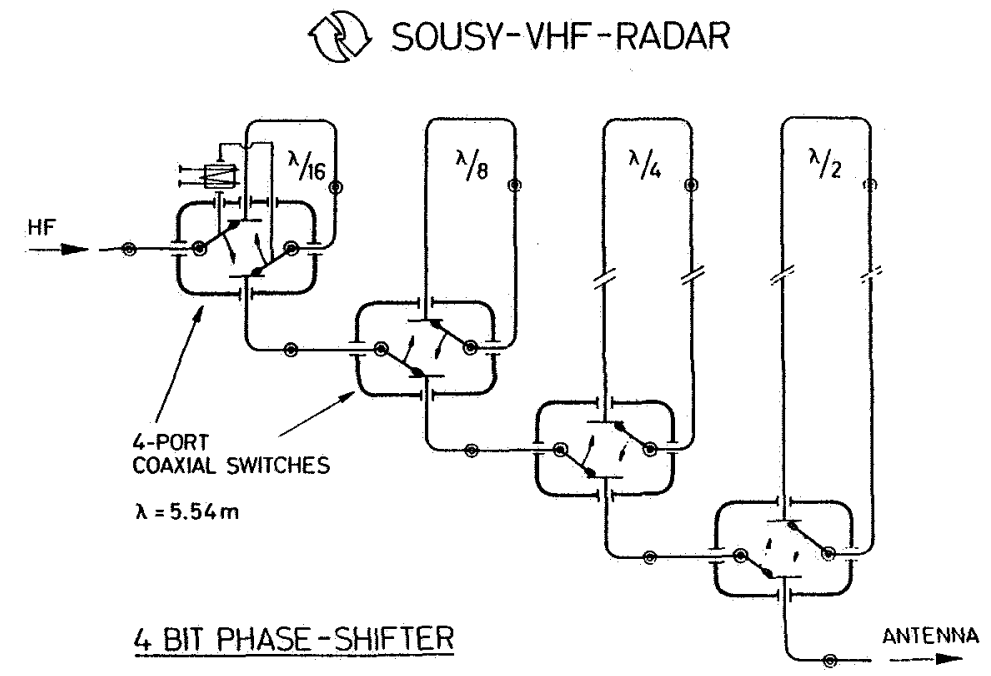

Figure 8, 4-bit phase shifter for the sousy radar antenna. Phase can be changed in multiples of $22.5^{\circ}$. 


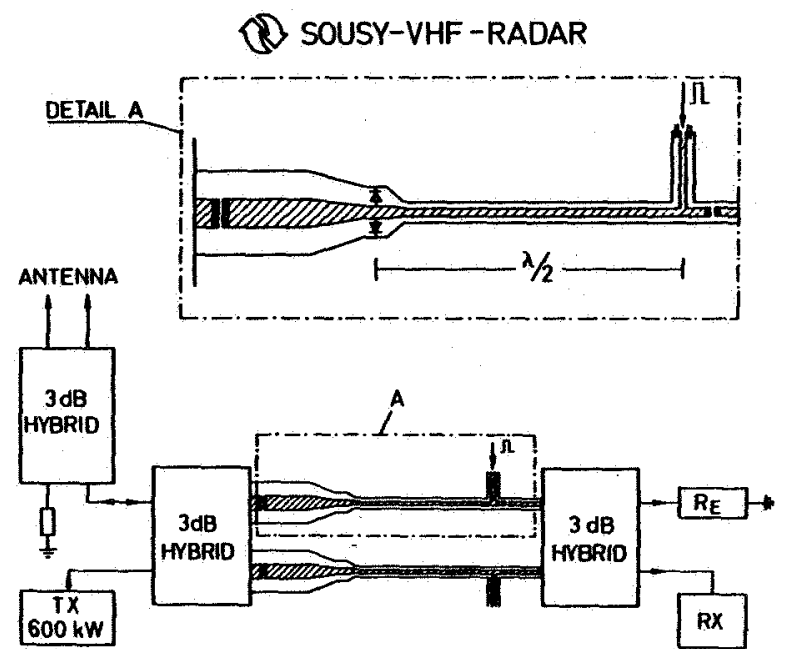

Figure 9. Scheme of the TR switch. Switching time is $8 \mu \mathrm{s}$.

The quality of the TR switch can be estimated by measuring the decoupling between the transmitter $\mathrm{TX}$ and the resistor $\mathrm{R}_{\mathrm{E}}$. For the stationary system the resulting voltage values were $5.5 \mathrm{kV}$ at the transmitter and $11 \mathrm{~V}$ at the resistor, corresponding to $54 \mathrm{~dB}$. With the additional decoupling of $30 \mathrm{~dB}$ of the second hybrid, a total decoupling of more than $80 \mathrm{~dB}$ to the receiver was proved.

The recovery time of the TR switch is less than $8 \mu \mathrm{s}$, enabling measurements from a lowest height level of about $1.2 \mathrm{~km}$. The bandwidth of the TR switch is several MHz.

\section{OBSERVATTONAL RESULTS}

In 1980 and 1981 the mobile SOUSY radar was operated for the first time at the Arecibo observatory in Puerto Rico. The telescope at the observatory is a unique instrument consisting of a large dish with a diameter of $300 \mathrm{~m}$; line feeds and point-source feeds are installed on a platform $150 \mathrm{~m}$ above the base of the dish. This system can be steered within $12.5^{\circ}$ off vertical. The SOUSY VHF transmitter and receiver were connected to a special log-periodic feed antenna, which was installed on the feed arm of the platform to illuminate the dish. This antenns configuration has a beam width of $1.6^{\circ}$ with an antenna gain of $41 \mathrm{~dB}$.

In 1981 , observations were carried out sporadically at different times during the day in order to analyze short-term events (RUSTER and KIOSTERMEYER, 1983) and to investigate structures and scattering mechanisms (ROTTGER et al., 1983). In general, significant atmospheric radar echoes have been observed in the stratosphere up to $25 \mathrm{~km}$ and from 60 to $90 \mathrm{~km}$ in the mesosphere.

The most interesting results concern the characteristics of mesospheric structures indicating two different types of layers. The contour plot (Figure 10) presents details of the height and time variation of the echo occurrence for a period of about one hour. The structures above $80 \mathrm{~km}$ can be described as cloud-like whereas those below as thin laminated sheets. This distinct separation into two different echo regions is also clearly expressed by the different shapes of the observed Doppler spectra. In Figure 11 the profiles of 


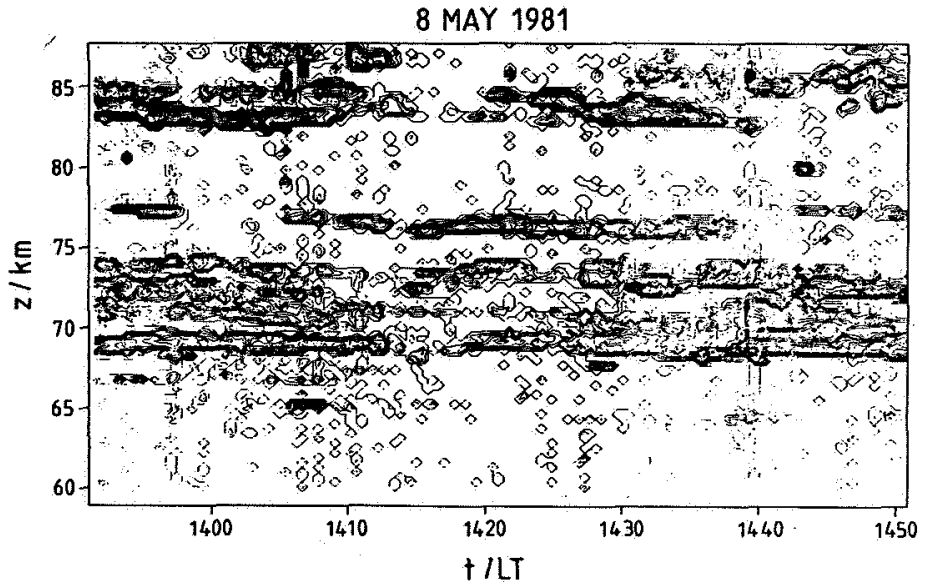

Figure 10. Mesospheric structures indicating two different types of layers measured in May 1981 with the mobile SOUSY radar in Arecibo, Puerto Rico.

the spectral intensity (grey scale) are plotted for the zonal and meridional component of the wind system. Below $80 \mathrm{~km}$ a strong directional shear is observed with a change of the wind direction of more than $90^{\circ}$ within a height interval of $6 \mathrm{~km}$. The spectra are extremely narrow in contrast to the broad spectra above $80 \mathrm{~km}$.

On May 29, measurements were carried out to investigate further details of the scattering mechanism of these structures (Figure 12). For this purpose the beam direction was changed in steps of 1.7 degrees from the vertical to $6.8^{\circ}$ of $f$ zenith. For five different examples the height integrated power was calculated 1355 LT

8 MAY 1981 $1435 \mathrm{LT}$
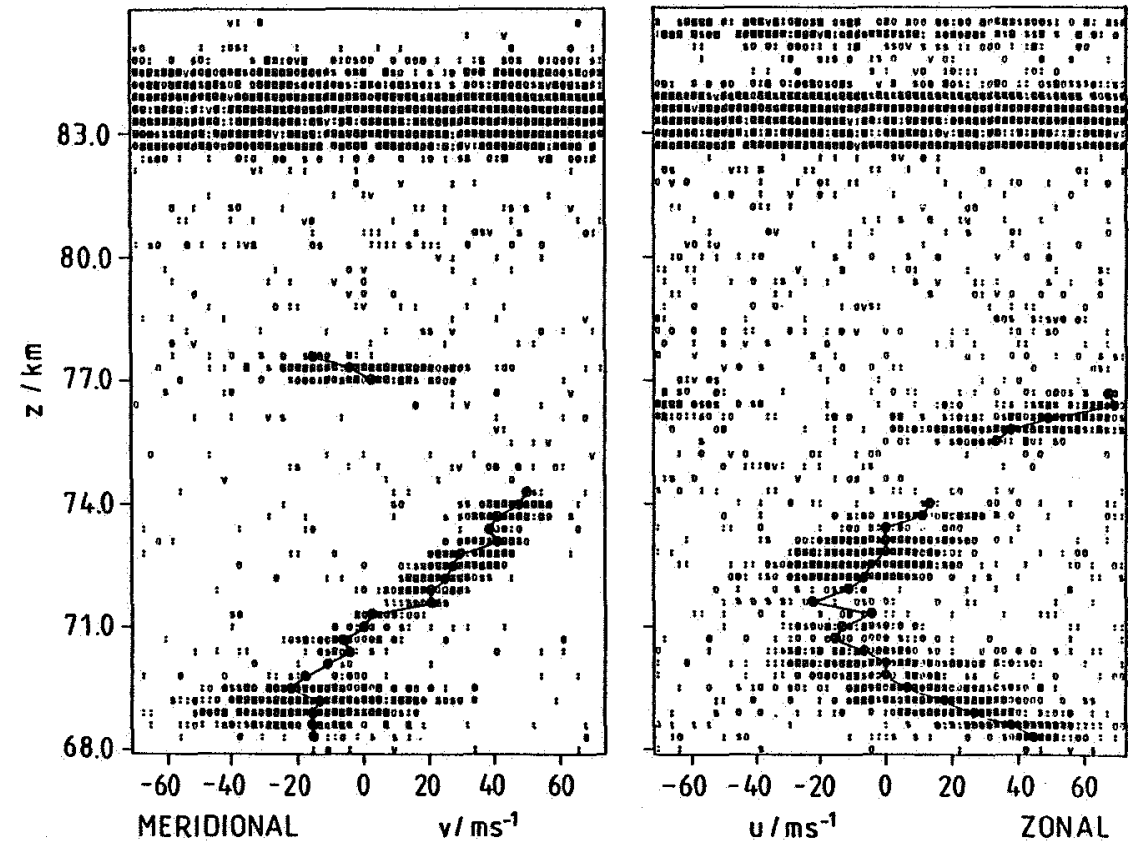

Figure 11. Intensity plots of mesospheric echo power spectra versus height measured in May 1981 with the mobile Sousy radar in Arecibo, Puerto Rico. 


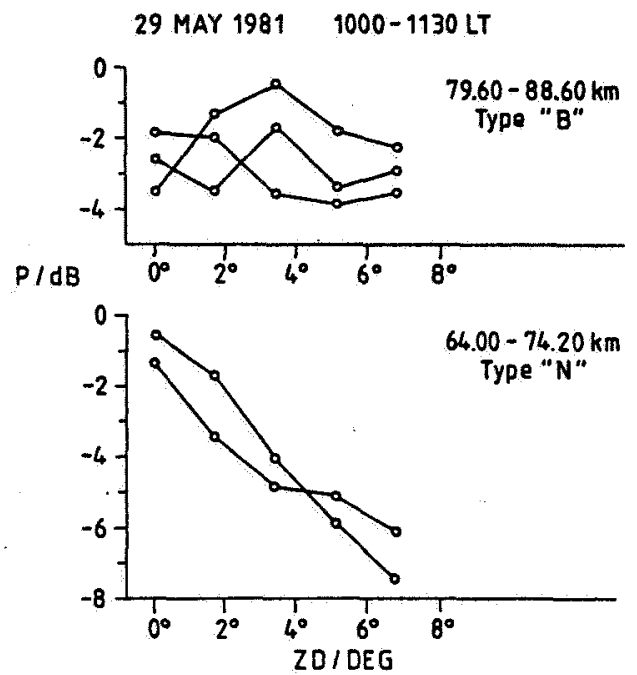

Figure 12. Aspect sensitivity of mesospheric signals measured

in May 1981 with the mobile SOUSY radar in Arecibo, Puerto Rico.

for both height regions and plotted as a function of the antenna zenith distance. Within the altitude range from 64 to $74 \mathrm{~km}$ a strong aspect sensitivity of about $1 \mathrm{~dB}$ per degree was observed. Above $80 \mathrm{~km}$, however, no significant variation in the echo power was measured during the change of the beam direction. The respective power spectra resulting from these echoes show the same significant differences as presented in Figure 11. In particular, the narrow spectra below $80 \mathrm{~km}$ and the broad ones above that height seem to indicate that turbulent structures are mainly present in the upper height interval giving rise to isotropic scatter. In the lower altitude range, however, laminated layers dominate causing partial reflections.

The airflow over and around mountains was one of the scientific problems selected for a major field study during the Global Atmospheric Research Program, which led to the Alpine Experiment (ALPEX) conducted in 1982 in Europe. Within the subprogram MERKUR designed for sicudying mesoscale phenomena, measurements have been carried out using the mobile SOUSY VHF-radar near Rosenheim in Bavaria, Germany (CZECHOWSKY et al., 1982; WEBER and RUSTER, 1982; WEBER et al., 1982). North and south of the radar site wind observations were performed by the German Weather Service and the Meteorological Institute of the University of Karlsruhe. During special observational periods additional in situ measurements by airplanes were carried out. These parallel measurements, therefore, offer the opportunity to compare the results obtained by the different techniques and to study the wind variation on a north-south baseline. Figure 13 shows the observed height profiles of the wind speed and wind direction. The solid line represents the VHF radar data, the dashed line the radiosonde data from Thalreit ( $5 \mathrm{~km}$ south), the crosses the radiosonde data from Munich ( $54 \mathrm{~km}$ northwest), the open and closed circles refer to the ascending and descending part of the flight measurements. This comparison shows a good agreement of the overall wind profile. The differences, in particular, result from the variations in time and location at which the data were taken. Differences of 1 hour and a few kilometers, respectively, can lead to variations in the wind field of up to $10 \mathrm{~m} \mathrm{~s}^{-1}$.

\section{FUTURE PROGRAMS}

The mobile radar is now prepared for operation during the MAP/WINE campaign 


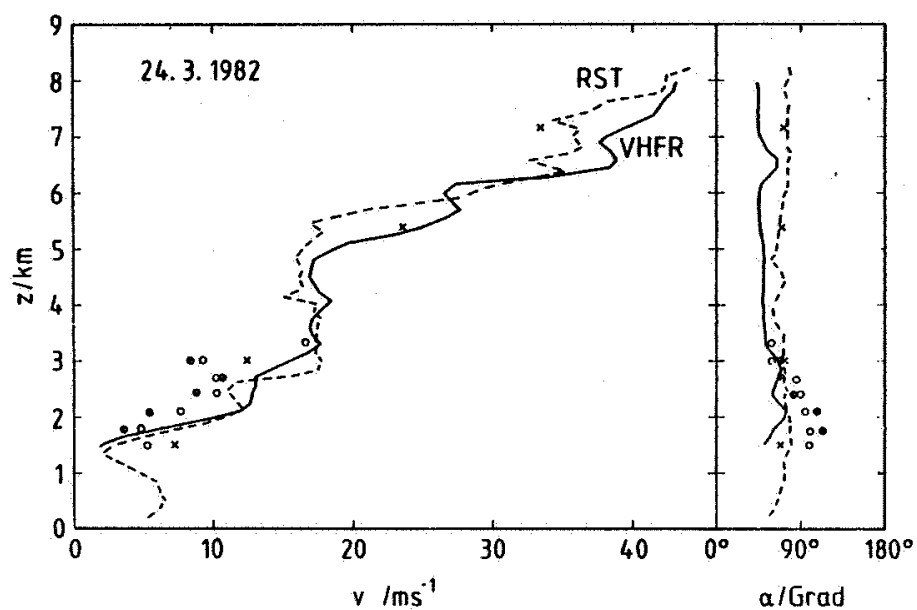

Figure 13. Height profiles of wind speed and direction compared with results from radiosondes from Munich and Thalreit measured with the mobile SOUSY radar system in March 1982 near Rosenheim, Bavaria during the Alpine Experiment (ALPEX).

and will be located on Andoya (Norway) during the winter season 1983/84. For the first time the final average power-aperture-product of $7.1 \times 10 \mathrm{Wm}(200$ $\mathrm{kW}, 4 \%$ duty cycle, $35.5 \mathrm{~dB}$ gain) will be available during this program. The scientific goals can be summarized as follows:

(1) Investigation of the morphology of tidal waves, gravity waves and turbulent structures in the winter mesosphere.

(2) The study of sudden stratospheric wamings, their temporal and spatial developments and their effect on structural parameters and dynamics of the mesosphere.

Starting in 1985 joint experiments are planned together with the EISCAT and Heating facilities near Tromso (Norway).

REFEREN CES

Balsley, B. B., W. L. Ecklund, D. A. Carter and P. E. Johnston (1979), The Poker Flat MST radar: First results, Geophys. Res. Lett., 6, 921-924.

Czechowsky, P. and K. Meyer (1980), Das Antennensystem des SOUSY VHF Radars, Report MPAE-T-00-80-19, Max-P1anck-Institut fur Aeronomie, KatlenburgLindau.

Czechowsky, P., R. Ruster and G. Schmidt (1979), Variation of mesospheric structures in different seasons, Geophys. Res. Lett., 6, 459-462.

Czechowsky, P., R. Ruster and G. Schmidt (1982), VHF-Radarmessungen wahrend ALPEX, Annalen der Meteorologie, 19, 124-126.

Dolph, C. L. (1946), Proc. I.R.E., 34.

Heilmann, A. (1970), Antennen II, L-I-Hochschultaschenbucher 534/534a, Bibliographisches Institut, Mannheim/Wien/Zurich, 55-58. 
Rottger, J., P. Czechowsky, R. Ruster and G. Schmidt (1983), VHF radar observations of wind velocities at the Arecibo Observatory, J. Geophys., 52, 34-39.

Rottger, J. and G. Schmidt (1979), High-resolution VHF radar sounding of the troposphere and stratosphere, IEEE Trans. Geosc. Electr., GE-17, 182-189.

Rottger, J. and R. A. Vincent (1978), VHF radar studies of tropospheric velocities and irregularities using spaced antenns techniques, Geophys, Res. Lett. . 5, 917-920.

Ruster, R, and J. Klostermeyer (1983), VHF radar observations of KelvinHelmholtz instability in a subtropic jet stream, Geophys. Astrophys. Fluid Dynamics (in press).

Schmidt, G., R. Ruster and P. Czechowsky (1979), Complementary code and digital filtering for detection of weak VHF radar signals from the mesosphere, IEEE Trans. Geosc. Electr., GE-17, 154-161.

Unitrode (1968), Application of PIN-diodes in high power duplexers, Application Note $\mathrm{M}-139$.

Weber, G. R. and R. Ruster (1982), Occurrence of a dry front over the Alpine region and Central Europe, Preliminary results of ALPEX (WMO).

Weber, G. R., R. Ruster and J. Klostermeyer (1982), VHF-Radarbeobachtungen im Voral pengebiet, Annalen der Meteorologie, 19, 99-101. 